\title{
Effect of Adhesive Type and Overlap Length on the Mechanical Resistance of a Simple Overlap Adhesive Joint
}

\author{
J. Monteiro' ${ }^{1}$ R. M. Salgado ${ }^{2}$, T. da Rocha ${ }^{3}$, G. Pereira ${ }^{4}$, \\ E. A. S. Marques ${ }^{5 *}$, R. J. C. Carbas ${ }^{6}$, L. F. M. da Silva ${ }^{7}$ \\ ${ }^{1}$ Department of Mechanical Engineering, Faculty of Engineering, University of Porto, Rua Dr. \\ Roberto Frias, 4200-465 Porto, Portugal (up201604679@fe.up.pt); 2Department of \\ Mechanical Engineering, Faculty of Engineering, University of Porto, Rua Dr. Roberto Frias, \\ 4200-465 Porto, Portugal (up201603995@fe.up.pt); ${ }^{3}$ Department of Mechanical Engineering, \\ Faculty of Engineering, University of Porto, Rua Dr. Roberto Frias, 4200-465 Porto, Portugal \\ (tomas.freitas.rocha@gmail.com); ${ }^{4}$ Department of Mechanical Engineering, Faculty of \\ Engineering, University of Porto, Rua Dr. Roberto Frias, 4200-465 Porto, Portugal; ${ }^{5}$ INEGI- \\ Institute of Science and Innovation in Mechanical and Industrial Engineering, Faculty of \\ Engineering campus, Rua Dr. Roberto Frias, 4200-465 Porto, Portugal (emarques@fe.up.pt) \\ ORCID 0000-0002-2750-8184; ${ }^{6}$ Department of Mechanical Engineering, Faculty of \\ Engineering, University of Porto, Rua Dr. Roberto Frias, 4200-465 Porto, Portugal; INEGI- \\ Institute of Science and Innovation in Mechanical and Industrial Engineering, Faculty of \\ Engineering campus, Rua Dr. Roberto Frias, 4200-465 Porto, Portugal (carbas@fe.up.pt) \\ ORCID 0000-0002-1933-0865; 7Department of Mechanical Engineering, Faculty of \\ Engineering, University of Porto, Rua Dr. Roberto Frias, 4200-465 Porto, Portugal \\ (lucas@fe.up.pt) ORCID 0000-0003-3272-4591
}

\begin{abstract}
The present study focuses on the experimental determination of the mechanical behaviour of simple lap joints subjected to quasi-static tensile loads. Four different specimens were tested, resulting from the combination of two different adhesives (ductile and brittle) and two distinct overlap lengths. Cohesive fractures were observed on all specimens, which allowed for a direct comparison of experimental results and failure load prediction using analytical criteria adequate for adhesive joints. Three different criteria were used to predict the failure load, the Volkersen criterion, generalized yielding of adhesive and the adherend yielding criterion. The predictions based on the Volkersen criterion were found to agree well with experimental values obtained for the more brittle material. Moreover, increasing overlap length for the same material only led to a slight increase of the failure load of the joint. However, for the ductile material it was the generalized yielding criterion that better agreed with experimental results, where a significant and linear increase of the failure load was observed with increased overlap length. These results provide valuable insights for material selection and joint design procedures for adhesive joints loaded under large mechanical demands.

Author Keywords. Adhesive Joints, Mechanical Properties, Failure Criteria, Experimental Tests.

Type: Research Article

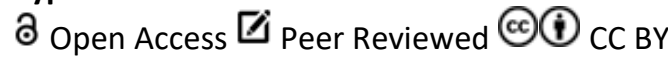

\section{Introduction}

One of the main advantages of adhesive bonding lies in the fact that it allows for a stress distribution which is more uniform than that obtained with other traditional methods of joining, such as riveting, fastening or welding. In addition, if properly designed, adhesive joints offer an increased potential for reduced weight and cost of the completed bonded structure. It is this set of advantages that have led to an increase in the usage of adhesive bonded joints 
in many technological manufacturing sectors, such as the automotive and aerospace industries.

The single lap joint (SL), composed of two flat specimens joined by adhesive, is the most commonly used adhesive joint, mainly due to its simplicity and relative efficiency because it loads mainly the adhesive in shear contrarily to other types of joints such as the T-joint (da Silva and Adams 2002). However, one of the problems associated to this type of joint is the fact that its stress distribution (both in shear and peel) is concentrated at the ends of the overlap. This leads to premature failure of the joint at the ends of the overlap, especially if a relatively brittle material is used as an adhesive. There are several parameters that affect the joint strength behaviour, such as the type of adhesive and adherend, adhesive thickness, overlap length, among many others. To be able to predict the strength of given SL configuration for design purposes it is necessary to know not only the mechanical properties of the materials but also understand how the geometrical parameters of a SLJ contribute to the joint behaviour.

The effect of adhesive properties on joint behaviour can be assessed by studying the stress distribution of a SLJ. This is possible because the joint strength is directly linked to stresses that are acting on the adhesive and the adhesive layer. Generally, joints with flexible adhesives have a more uniform stress distribution and high elongation, while brittle adhesives will generate high stress concentrations at the ends of overlap and lead to a lower elongation before failure. Flexible adhesives have better resistance to peel, fatigue, crack propagation, and impact loads. However, flexible adhesives usually have a lower cohesive strength. Brittle adhesives have a lower toughness and higher modulus. In general, adhesives are extensively employed in high performance structural applications to resist fatigue and impact loads, minimizing stress concentrations that can conduct to premature damage (Petrie 2000; da Silva, Öchsner, and Adams 2018).

The properties of the adherend also have an important influence on the joint stress distribution (Shishesaz and Hosseini 2020; Karachalios, Adams, and da Silva 2013). Nonuniform stress distribution along the overlap in the adhesive is caused by the relative displacement of the adherends due to the strain in the adherends. The Young's modulus and thickness of each adherend are important factors in the shear stress distribution. For joints made with flexible adherends and stiff adhesives, the bonded area will tend to deform elastically under load. This distortion causes cleavage stress at the ends of the overlap reducing the joint strength. Thicker adherends are more rigid, and the distortion is not as much a problem as with thin adherends. Adherend yielding can cause premature failure of the joint, when the stress reaches the yield point of the adherend creating a plastic hinge at the edge of the overlap. This leads to a large plastic deformation of the adherend and, since the maximum adhesive strain is limited, the joint fails when the maximum adhesive strain is reached (da Silva, Öchsner, and Adams 2018; da Silva et al. 2006; Grant, Adams, and da Silva 2009). Volkersen (1938) used the differential straining or shear lag analysis to calculate the stresses acting on the adhesive layer. When the joint is loaded it deforms according to the shape shown in Figure 1. The shear stress peaks at the ends of the overlap and is minimum at the middle. 


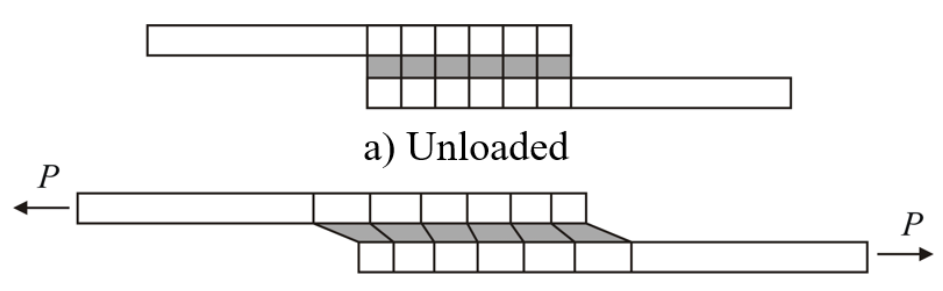

b) Loaded

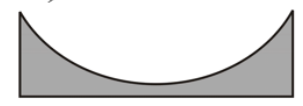

c) Shear stress on the adhesive layer

Figure 1: Differential straining and stresses acting on the adhesive layer (Volkersen 1938)

Another important parameter that influences the joint strength is the overlap length. The effect of the overlap length depends on the type of adhesive and on the adherend yielding. For elastic adherends and ductile adhesive (more than $20 \%$ shear strain to failure), a wellsuited failure criterion is the global yielding of the adhesive. This can be calculated using Equation (1).

$$
\tau_{y}=\frac{P}{b l}
$$

Where $P$ is the load, $b$ is the joint width, $/$ is the overlap length and $\tau_{y}$ is the shear yield strength of the adhesive (see Figure 3 ). The joint strength, $P$, is approximately proportional to the overlap because the adhesive can deform plastically, and all the overlap is sustaining the load. For adherends which deform significantly and brittle adhesives, joint strength is not proportional to the overlap due to stress concentrations at the ends of the overlap. For adherends that yield, failure occurs when the yield point of the adherend is exceeded (da Silva, Öchsner, and Adams 2018; Grant, Adams, and da Silva 2009). For SLs there is certain value of overlap length above which there is no strength advantage, and for large overlap lengths, there is always a central region of the overlap that is practically unloaded. This occurs when brittle adhesives are used, that is, adhesives without plastic deformation. However, if the adhesive shows plastic behaviour, the failure stress has been shown to increase proportionally to the overlap length (Campilho, Moura, and Domingues 2005; Nunes et al. 2016; Banea et al. 2017).

Adams, Comyn, and Wake (1997) proposed a simple methodology to determine the strength of SLJs as function of the overlap and the adherend thickness (Figure 2). As stated before, the load corresponding to the total plastic deformation of the adhesive can be calculated assuming global yielding by:

$$
P_{G Y}=\tau_{y} b l
$$

where $P_{G Y}$ is the failure load of the adhesive due to global yielding, $\tau_{y}$ is the shear yield strength of the adhesive, $b$ is the joint width and $l$ is the overlap length. The tensile stress $\left(\sigma_{t}\right)$ on the adherend, caused by a load $P$ is:

$$
\sigma_{t}=P / b t_{s}
$$

where $t_{s}$ is the adherend thickness. The stress at the inner adherend surface $\left(\sigma_{s}\right)$ due to the bending moment $M$ ca be calculated by:

$$
\sigma_{s}=6 M / b t_{s}^{2}
$$

where $M=k P t_{s} / 2$, according to the work of Goland and Reissner (1944). The variable $k$ is the bending moment factor which reduces (from unity) as the lap rotates under load. The 
stress present in the adherend can be calculated by adding the direct stress and the bending stress. The maximum load that leads to adherend yield $\left(P_{A Y}\right)$ is:

$$
P_{A Y}=\sigma_{y} b t_{s} /(1+3 k)
$$

where $\sigma_{y}$ is the yield strength of the adherend. For low loads and short overlaps, $k$ can be assumed to be approximately 1 , giving:

$$
P_{A Y}=\sigma_{y} b t_{s} / 4
$$

However, for joints which are much longer than they are thick, such that $l / t_{s} \geq 20$, the value of $k$ decreases until it tends to zero, leading to:

$$
P_{A Y}=\sigma_{y} b t_{s}
$$

From a certain value of $I / t_{s}>20$, the strength increase that can be obtained is very limited and increasing the overlap length any further is inefficient.

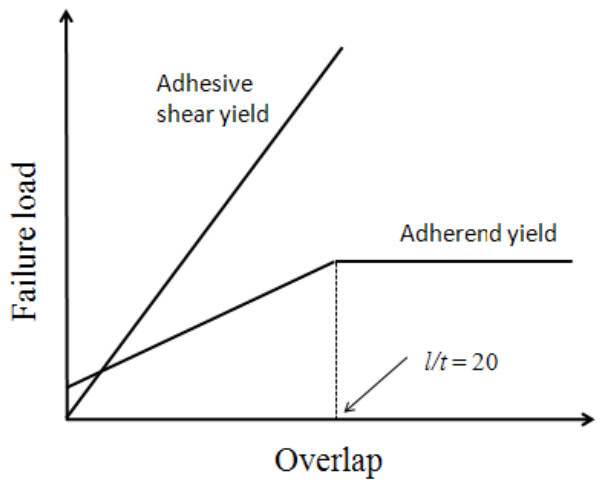

Figure 2: Methodology to predict the overlap corresponding to adherend yield (da Silva, Öchsner, and Adams 2018)

The current work aims to assess the influence of different adhesive materials and different overlap lengths on the mechanical behaviour of structural adhesive joints. To allow for a study of the effect of adhesive in the joint behaviour, two types of adhesive with clearly distinct failure mechanisms were used: SikaForce 7818 L7 (Sika, Portugal) and AV138/HV998 (Huntsman, Switzerland). The first of these adhesives has large strain at failure but a quite low failure stress while the latter is stronger, but very brittle. A similar approach was made with regards to the selection of the overlap length of the joints. Two joint configurations with different overlap lengths were tested, with the largest configuration having an overlap length four times higher than the smaller specimen configuration. In addition, this work also provided insights into the optimal manufacturing methods for an adhesive joint, from the preparation of the bonded surfaces to the application of the adhesive.

\section{Experimental Procedure}

\subsection{Materials}

High strength steel (DIN $55 \mathrm{Si}$ 7) adherends were used in all joints under study. Given that the aim of this study was to evaluate the strength of different adhesives and joint configurations, the use of this type of steel ensures that plastic deformation of adherend does not occur throughout the test. The mechanical properties of high strength steel used are presented in Table 1.

\begin{tabular}{ccc}
\hline $\begin{array}{c}\text { Young's Modulus } \\
\text { [GPa] }\end{array}$ & Poisson's ratio & Yield stress [Mpa] \\
\hline 210 & 0.3 & 1100 \\
\hline
\end{tabular}

Table 1: Relevant mechanical properties of the substrate 
In Table 2, the mechanical properties of the adhesives used are presented, allowing for a direct comparison of the adhesive's stiffness, strength, and strain. SikaForce 7818 L7 adhesive, due to its large shear strain is classified as a ductile adhesive, while the Araldite AV138/HV998 adhesive has a much lower strain at failure, thus being classified as a stiff and brittle adhesive. To simplify the analysis from this point on, the two adhesives will be referred according to their mechanical behaviour (ductile or brittle), as indicated in Table 2.

\begin{tabular}{cccccc}
\hline Adhesive & $\begin{array}{c}\text { Adhesive } \\
\text { behaviour }\end{array}$ & $\begin{array}{c}\text { Young's } \\
\text { Modulus [MPa] }\end{array}$ & $\begin{array}{c}\text { Poisson's } \\
\text { ratio }\end{array}$ & $\begin{array}{c}\text { Yield shear } \\
\text { stress [MPa] }\end{array}$ & $\begin{array}{c}\text { Maximum } \\
\text { shear strain } \\
\text { [\%] }\end{array}$ \\
\hline SikaForce 7818 L7 & Ductile & 2500 & 0.38 & 15 & $>20$ \\
\hline Araldite ${ }^{\circledR}$ AV138/HV998 & Brittle & 4590 & 0.36 & 32 & 5 \\
\hline
\end{tabular}

\subsection{Joint geometry}

Two SL overlap lengths were evaluated for each adhesive type (geometry presented in Figure 3). These overlap lengths ( 12.5 and $50 \mathrm{~mm}$ ) were selected to evaluate the influence of stress distribution on joint strength for two different adhesives. Table 3 presents the dimensions of each joint and the designation attributed to it.

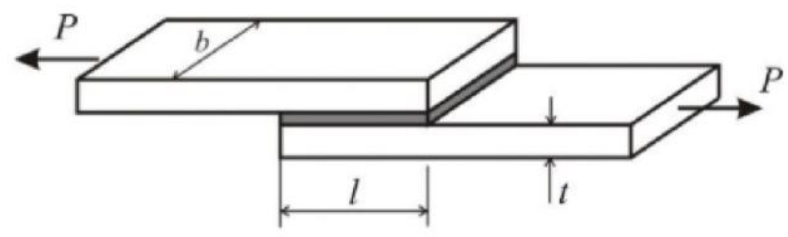

Figure 3: Geometry of a SL

\begin{tabular}{|c|c|c|c|c|c|c|}
\hline $\begin{array}{c}\text { Joint } \\
\text { designation }\end{array}$ & $\begin{array}{c}\text { Failure } \\
\text { mechanism }\end{array}$ & $\begin{array}{c}\text { Overlap } \\
\text { length (I) } \\
{[\mathrm{mm}]}\end{array}$ & $\begin{array}{c}\text { Substrate } \\
\text { length }[\mathrm{mm}]\end{array}$ & $\begin{array}{l}\text { Width (b) } \\
\text { [mm] }\end{array}$ & $\begin{array}{l}\text { Adherend } \\
\text { thickness } \\
\text { (t) }[\mathrm{mm}]\end{array}$ & $\begin{array}{c}\text { Adhesive } \\
\text { thickness } \\
\text { [mm] }\end{array}$ \\
\hline Ductile_12.5mm & \multirow{2}{*}{ Ductile } & 12.5 & 107.5 & \multirow{4}{*}{25} & \multirow{4}{*}{2} & \\
\hline Ductile_50mm & & 50 & 145 & & & \\
\hline Brittle_12.5mm & \multirow{2}{*}{ Brittle } & 12.5 & 107.5 & & & 0.2 \\
\hline Brittle_50mm & & 50 & 145 & & & \\
\hline
\end{tabular}

Table 3: Joint dimensions and designation

\subsection{Surface treatment}

Due to the influence of substrate surface quality on the level of adhesion between the adhesive and the substrate, a set of procedures were carried out in order to modify the topography of the surfaces and remove contaminants. The first step consisted on sanding the surfaces using a sandpaper of intermediate granulometry. This operation led to an increase of the surface roughness and the area of contact between adhesive and substrate. Having concluded this step, the overlap area of the substrate was cleaned with acetone to remove residues and particles resulting from the sanding process and also to ensure that no grease or possible contaminants are present on the surface.

\subsection{Joint manufacture}

Once the surface treatment was completed, the lower substrates of the SL were placed in a mould, as shown in Figure 4, and aligned using pins, shims and positioner blocks. Then, the two adhesives were deposited using different techniques. The homogenization of the mixture for the brittle adhesive was carried out in a centrifugal mixer. This adhesive was then applied manually with a spatula. 


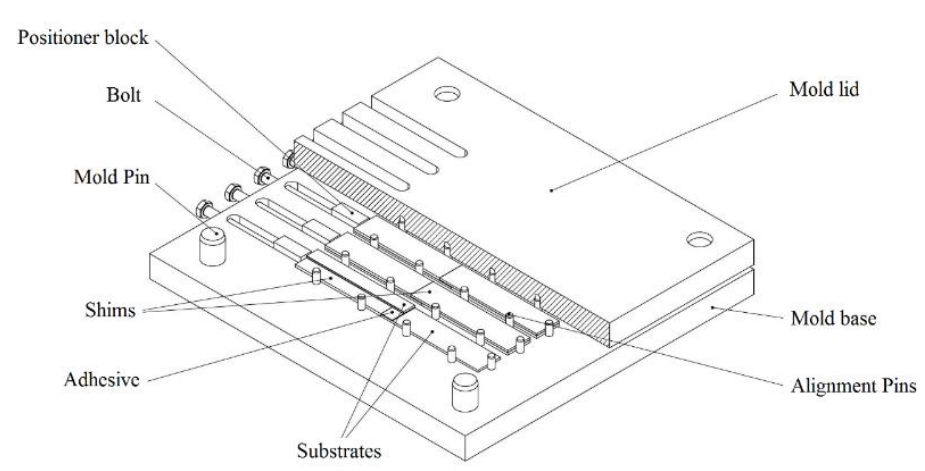

Figure 4: Joint manufacturing mould

The last step of the manufacturing process is to position the upper substrates over the adhesive layer and close the mould. The contact between the two plates is made progressively, ensuring that air can escape from the overlap area. The exact thickness of $0.2 \mathrm{~mm}$ of adhesive in the overlap area is ensured with the use of shims.

The cure procedure was the same for both adhesives. Pressure was applied on the mould in order to ensure uniform bondline thickness and cured under ambient conditions $\left(23^{\circ} \mathrm{C}\right.$ and moisture of $55 \%$ ) for 24 hours.

\subsection{Test method}

The experimental tests were performed at room temperature using an INSTRON ${ }^{\circledR}$ model 3367 universal testing machine, with a load cell of $30 \mathrm{kN}$ and at a constant displacement rate of $1 \mathrm{~mm} / \mathrm{min}$. At least five joints were tested to failure for each condition (for each overlap length and adhesive type).

\section{Failure Load Predictions}

In order to correctly analyse the results obtained in experimental tests, it was necessary to first predict the results based on theoretical criteria. Therefore, three different criteria were studied: Volkersen, generalized yield of adhesive, and adherend yielding criterion.

The need to consider three different criteria in the design of an adhesive joint highlights the fact that an universal criterion suitable for all adhesive materials and joint configurations does not exist, requiring the designer to fully understand the capabilities of each design criterion. Table 4 shows the failure load prediction for each joint, based on the three different criteria.

\begin{tabular}{cccc}
\hline & \multicolumn{3}{c}{ Failure Load [kN] } \\
\cline { 2 - 4 } Joint designation & Volkersen & $\begin{array}{c}\text { Generalized } \\
\text { yielding of } \\
\text { adhesive }\end{array}$ & $\begin{array}{c}\text { Adherend } \\
\text { yielding }\end{array}$ \\
\hline Ductile_12.5mm & 3.70 & 4.69 & 20.12 \\
\hline Ductile_50mm & 5.10 & 18.75 & 55 \\
\hline Brittle_12.5mm & 6.76 & 10 & 20.12 \\
\hline Brittle_50mm & 7.95 & 40 & 55 \\
\hline
\end{tabular}

Table 4: Failure load predictions based on each criterion

The calculations were performed using the Jointdesigner joint design software (https://jointdesigner.pt) (da Silva, Lima, and Teixeira 2009). This software provides several analytical analysis methods to predict joint strength and the stress distribution along the bondline of the bonded joints. More detailed descriptions of the different criteria presented can be found in works related to the design of adhesive joints (da Silva et al. 2009). 


\section{Results}

\subsection{Load-displacement curves}

Representative load-displacement curves are presented in Figure 5 for ductile and for the brittle adhesive in Figure 6 . The nonlinear behaviour observed for the joints bonded with ductile adhesive is due to the adhesive deformation and for joints bonded with brittle adhesive a linear behaviour can be seen, indicating that until the adhesive failure the adhesive remained in the elastic domain. Table 5 summarizes the failure load obtained experimentally for each joint.

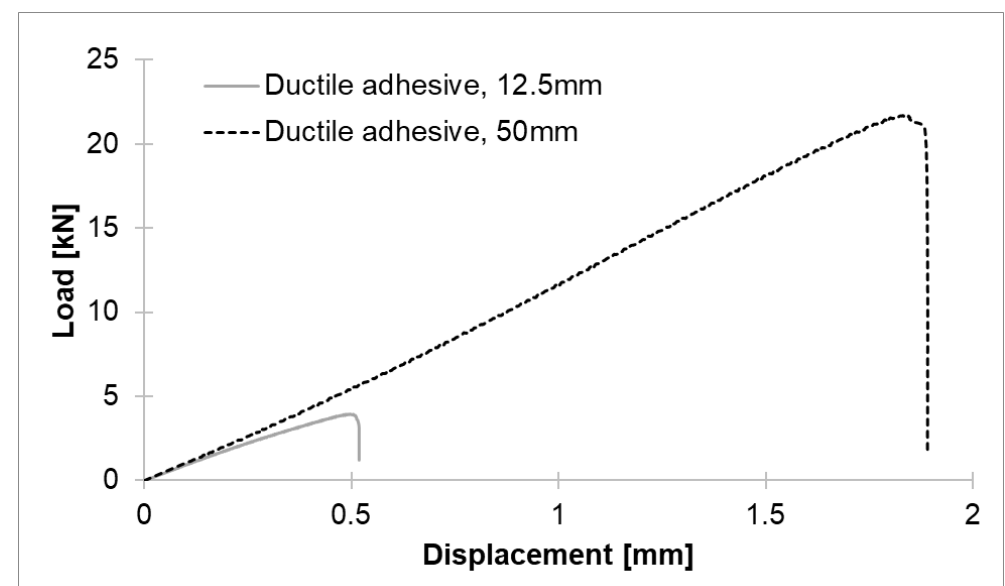

Figure 5: Representative load-displacement curves for the ductile adhesive

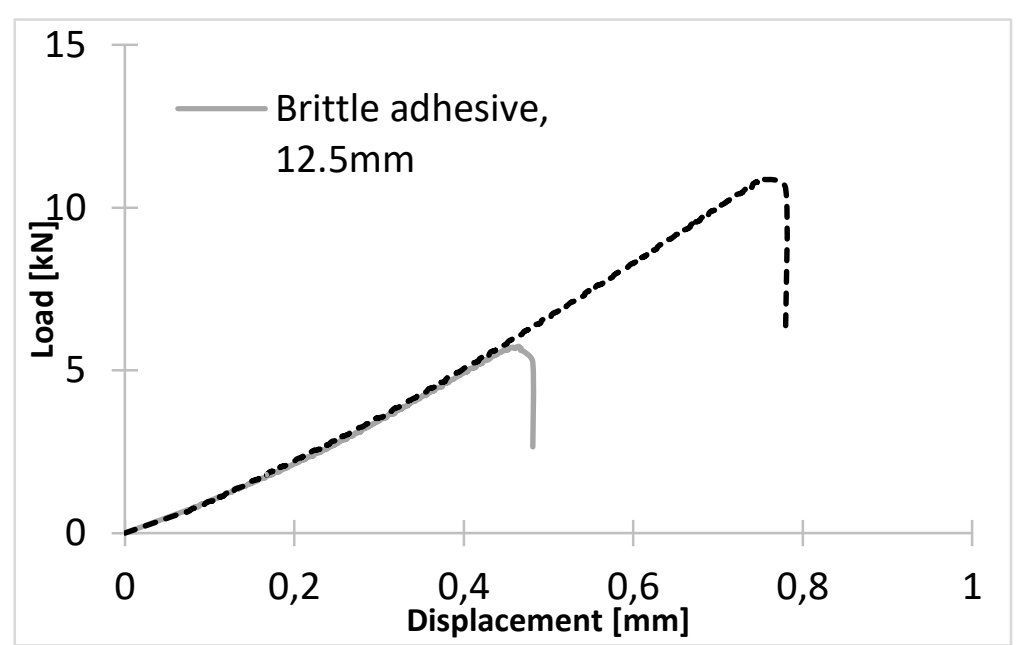

Figure 6: Representative load-displacement curves for the brittle adhesive

\begin{tabular}{ccc}
\hline Joint designation & Failure Load [kN] & Standard deviation [kN] \\
& & \\
\hline Ductile_12.5mm & 5.87 & 0.46 \\
\hline Ductile_50mm & 23.10 & 2.07 \\
\hline Brittle_12.5mm & 5.39 & 0.43 \\
\hline Brittle_50mm & 10.53 & 0.62 \\
\hline
\end{tabular}

Table 5: Failure load of each joint

\subsection{Failure surfaces}

The failure surfaces obtained for each tensile test were examined by visual inspection. Figure 7 and Figure 8 show the failure surfaces of the joints manufactured with the ductile and with 
the brittle adhesive, respectively. An analysis of the failure surfaces allows to identify the failure modes of the joint, evaluating the quality of the surface preparation used and explaining the obtained failure load.

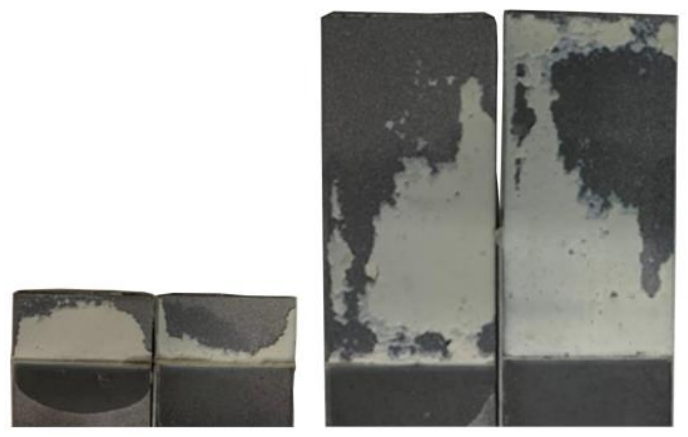

Figure 7: Failure surface of the joints Ductile_12.5mm (left) and Ductile_50mm (right)
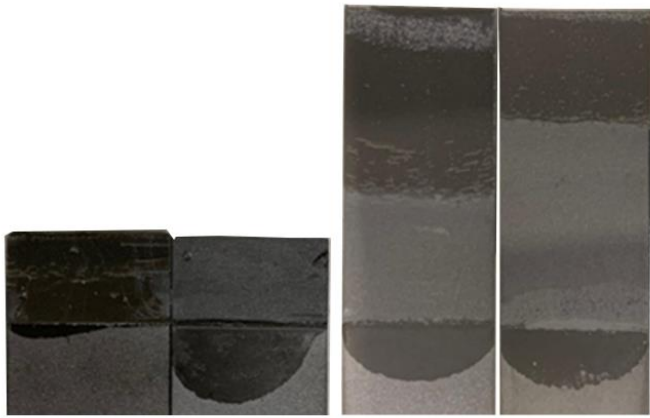

Figure 8: Failure surface of the joints Brittle_12.5mm (left) and Brittle_50mm (right)

The inspection of the failure surfaces showed the presence of a thin adhesive layer along the entire length of the bonded area for all tested joints. The presence of this layer allows to conclude that the failure was always cohesive in the adhesive, which indicates a correct preparation of the substrate surfaces. If, contrarily, the adhesive had completely detached from the substrates, an adhesive failure would have occurred. This situation must be avoided, as it leads to low joint strength. In addition, the interface strength is difficult to characterize, which makes it impossible to predict failure load using analytical models. This failure mode usually occurs when the preparation of the substrate surfaces is not adequate.

Furthermore, no plastic deformation of the adherend was observed, the steel used in the adherends has a yield stress that is much higher than the peel stresses that occur at the ends of overlap length during test.

\section{Discussion}

In order to determine which failure criteria most closely agrees with the experimental results, a graphical representation of failure load as a function of the overlap length was created for each adhesive.

\subsection{Ductile adhesive}

Figure 9 displays the experimental and analytical predictions for the failure load of the ductile adhesive, plotted as a function of the overlap length. 


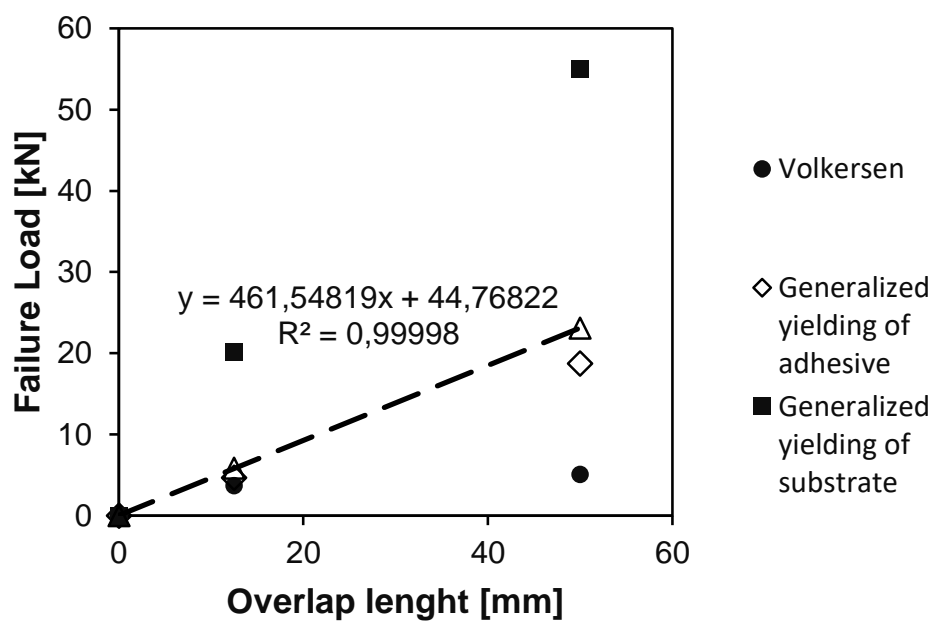

Figure 9: Failure load vs overlap length for the ductile adhesive

The experimental values of failure load increased with overlap length. Furthermore, the same increase shows a linear trend, as shown by the high coefficient of determination, $R^{2}$.

A comparison between the experimental curve and other related with failure criteria shows a very good agreement with the generalized yielding of adhesive criterion. This criterion is capable of accurately predicting results, with a percentage error equal or lower than $20 \%$ for both overlap lengths, as shown in Table 6. Furthermore, it shows that the ductility of this adhesive led to the yielding of adhesive layer along the entire overlap length, with failure occurring when maximum deformation is reached.

\begin{tabular}{|c|c|c|c|c|}
\hline \multirow[b]{2}{*}{ Joint designation } & \multirow[b]{2}{*}{$\begin{array}{c}\text { Failure } \\
\text { mechanism }\end{array}$} & \multicolumn{2}{|c|}{ Failure Load [kN] } & \multirow[b]{2}{*}{ \% Error } \\
\hline & & Experimental & $\begin{array}{c}\text { Generalized } \\
\text { yielding of } \\
\text { adhesive }\end{array}$ & \\
\hline Ductile_12.5mm & \multirow{2}{*}{ Ductile } & 5.87 & 4.68 & 20.2 \\
\hline Ductile_50mm & & 23.10 & 18.75 & 18.9 \\
\hline
\end{tabular}

Table 6: Comparison between experimental results and predictions obtained with the generalized yielding of adhesive criterion for the ductile adhesive

The discrepancy of the strength prediction based on the Volkersen criterion, regarding joint $D-L(I=50 \mathrm{~mm})$, is explained by an increased joint strength that is achieved with the redistribution and attenuation of the shear stress peaks, due to the increased plastic deformation. As such, an increase on overlap area proportionally leads to an increase of failure load for a joint subjected to shear load.

\subsection{Brittle adhesive}

Figure 10 shows experimental and predicted failure loads for the brittle adhesive, as a function of the overlap length. 


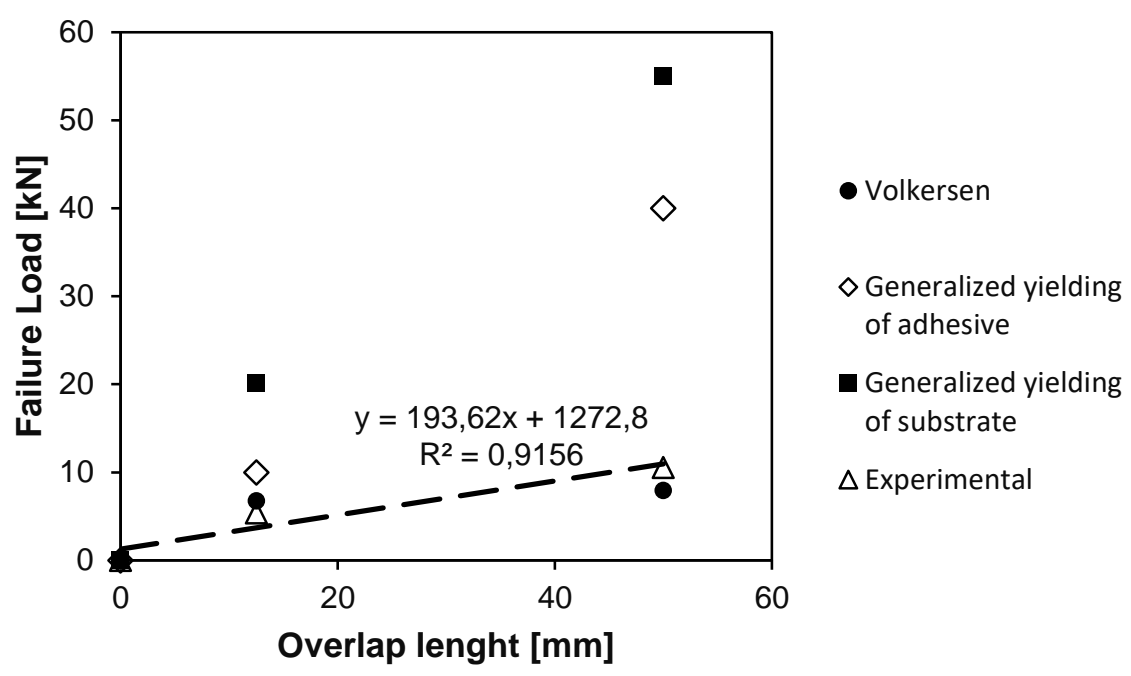

Figure 10: Failure load vs overlap length for the brittle adhesive

The experimental failure load values also show an increase of the failure load with the overlap length. However, a linear trend was not observed, owing to a relatively low value for the coefficient of determination, $\mathrm{R}^{2}$. On the contrary, comparing the two experimental values, this increase was attenuated for the highest value of overlap length.

For the brittle adhesive, the Volkersen criterion shows the best agreement with experimental results, as expected. This criterion was capable to predict the failure load for both joint lengths with an error percentage around $25 \%$, as shown in Table 7 . The values obtained strongly suggest that the adhesive does not exhibit significant plastic strain, leading to a more brittle failure process.

\begin{tabular}{|c|c|c|c|c|}
\hline \multirow{2}{*}{ Joint designation } & \multirow{2}{*}{$\begin{array}{c}\text { Failure } \\
\text { mechanism }\end{array}$} & \multicolumn{2}{|c|}{ Failure Load [kN] } & \multirow{2}{*}{ \% Error } \\
\hline & & Experimental & Volkersen & \\
\hline Brittle_12.5mm & \multirow{2}{*}{ Brittle } & 5.39 & 6.76 & 25.5 \\
\hline Brittle_50mm & & 10.53 & 7.95 & 24.5 \\
\hline
\end{tabular}

Table 7: Comparison between experimental results and predictions obtained with the Volkersen criterion for the brittle adhesive

The validity of the Volkersen criterion, which does not occur for the ductile adhesive, is explained by the inexistence of plastic strain, meaning that failure occurs when the shear stress acting on the limits of the overlap area equals the yield shear stress of this adhesive. The central area of the overlap is relatively unloaded and provides a small contribution to overall joint strength.

Joint strength is strongly influenced by the stress distribution along the overlap area and the mechanical properties of the adhesive. In this case, the stress concentrations at the ends of the overlap, that are intrinsically linked to the geometry of SLJ, are aggravated due to the usage of a brittle adhesive, thus, the area of adhesive that is effectively resisting the shear loads is significantly smaller than the overlap area, being restricted to the ends of the overlap. It thus can be concluded that an increase of overlap length has a reduced effect on strength increase of an overlap joint when compared with a joint using ductile adhesive.

\subsection{Analysis for both types of adhesive}

The generalized yielding of the substrate criterion has led to an overestimation of the failure load in all cases under study, which can easily be explained by the choice of a high strength steel substrate with high yielding strength. However, for joints where the substrates are 
weaker and can yield this criterion should not be overlooked as it provides very accurate results. In these cases, it is the excessive plastic deformation of the substrate that directly leads to failure of the adhesive layer and, consequentially, of the full joint.

The evolution observed for the failure load as a function of the overlap length explains the higher strength obtained for the largest overlap length when a ductile adhesive is used. Even though the yielding stress for the ductile adhesive is lower than that of the brittle adhesive, the generated stress distribution along the overlap is less severe and leads to this result.

It should be noted that these results are only valid for a joint loaded under a shear load (as is the case for the SLJs under study). Adhesive joints, when subjected at cleavage or peeling loads, create high peel stress levels, concentrated over small areas, leading to premature joint failure at low failure loads.

The slight discrepancy between the experimental and predicted results (as given by generalized yielding of ductile adhesive and the Volkersen criterion for brittle adhesive) may be explained by experimental factors, such as slightly different adhesive properties due to variations in the curing process and the presence of excess of adhesive at the ends of the overlap, among other factors.

\section{Conclusions}

In this work, the joint strength of SL was evaluated as a function of overlap length and for two different types of adhesives. Three different analytical criteria were used to predict the failure load of SLJs.

The main conclusions are the following:

- An increase of overlap length can lead to an approximately linear increase on joint strength for the joints bonded with ductile adhesives. That is, when the adhesive undergoes plastic deformation along the full overlap length.

- The failure load of SLJs bonded with a brittle adhesive was not found to follow this trend, with a limited improvement for the larger overlap length. With the increase of overlap length conducted to a slight increase of the failure load.

- The predictions based on the Volkersen criterion were found to agree well with experimental values obtained for the joints bonded with brittle adhesives.

- For the joints bonded with ductile adhesives, the generalized yielding criterion was found to reproduce the experimental data most accurately.

- The experimentally obtained fracture surfaces confirmed the failure mechanisms associated with each specimen and justify the importance of carefully designing and manufacturing an adhesive joint.

\section{References}

Adams, R. D., J. Comyn, and W. C. Wake. 1997. Structural adhesive joints in engineering. Springer Netherlands.

Banea, M. D., L. F. M. da Silva, R. Carbas, and R. D. S. G. Campilho. 2017. "Effect of material on the mechanical behaviour of adhesive joints for the automotive industry". Journal of Adhesion Science and Technology 31, no. 6 (march): 663-76. https://doi.org/10.1080/01694243.2016.1229842.

Campilho, R. D. S. G., M. F. S. F. de Moura, and J. J. M. S. Domingues. 2005. "Modelling single and double-lap repairs on composite materials". Composites Science and Technology 65, no. 13 (october): 1948-58. https://doi.org/10.1016/j.compscitech.2005.04.007. 
da Silva, L. F. M., and R. D. Adams. 2002. "The strength of adhesively bonded T-joints". International Journal of Adhesion and Adhesives 22, no. 4: 311-15. https://doi.org/10.1016/S0143-7496(02)00009-X.

da Silva, L. F. M., A. Öchsner, and R. D. Adams, eds. 2018. Handbook of adhesion technology. $2^{\text {nd }}$ ed. Cham: Springer. https://doi.org/10.1007/978-3-319-55411-2.

da Silva, L. F. M., R. J. C. Carbas, G. W. Critchlow, M. A. V. Figueiredo, and K. Brown. 2009. "Effect of material, geometry, surface treatment and environment on the shear strength of single lap joints". International Journal of Adhesion and Adhesives 29, no. 6 (september): 621-32. https://doi.org/10.1016/j.ijadhadh.2009.02.012.

da Silva, L. F. M., R. F. T. Lima, and R. M. S. Teixeira. 2009. "Development of a computer program for the design of adhesive joints". Journal of Adhesion 85, no. 12 (december): 889918. https://doi.org/10.1080/00218460903307761.

da Silva, L. F. M., T. N. S. S. Rodrigues, M. A. V. Figueiredo, M. F. S. F. de Moura, and J. A. G. Chousal. 2006. "Effect of adhesive type and thickness on the lap shear strength". Journal of Adhesion 82, no. 11 (november): 1091-115. https://doi.org/10.1080/00218460600948511.

Goland, M., and E. Reissner. 1944. "The stress in cemented joints". Journal of Applied Mechanics 66: A17-A27.

Grant, L. D. R., R. D. Adams, and L. F. M. da Silva. 2009. "Experimental and numerical analysis of single-lap joints for the automotive industry". International Journal of Adhesion and Adhesives 29, no. 4 (june): 405-13. https://doi.org/10.1016/j.ijadhadh.2008.09.001.

Karachalios, E. F., R. D. Adams, and L. F. M. da Silva. 2013. "Single lap joints loaded in tension with ductile steel adherends". International Journal of Adhesion and Adhesives 43 (june): 96-108. https://doi.org/10.1016/j.ijadhadh.2013.01.017.

Nunes, S. L. S., R. D. S. G. Campilho, F. J. G. da Silva, C. C. R. G. de Sousa, T. A. B. Fernandes, M. D. Banea, and L. F. M. da Silva. 2016. "Comparative failure assessment of single and double lap joints with varying adhesive systems". Journal of Adhesion 92, no. 7-9 (september): 610-34. https://doi.org/10.1080/00218464.2015.1103227.

Petrie, E. M. 2000. Handbook of adhesives and sealants. McGraw-Hill Professional.

Shishesaz, M., and M. Hosseini. 2020. "Effects of joint geometry and material on stress distribution, strength and failure of bonded composite joints: an overview". Journal of Adhesion 96, no. 12: 1053-121. https://doi.org/10.1080/00218464.2018.1554483.

Volkersen, O. 1938. "Die nietkraftverteilung in zugbeanspruchten nietverbindungen mit konstanten laschenquerschnitten". Luftfahrtforschung 15, no. 1/2: 41-47. 